\title{
ALGORITMOS GENÉTICOS APLICADOS NA CRIAÇÃO DE AGENDAS DE HORÁRIO SEMANAL DE AULAS
}

\section{GENETIC ALGORITHMS APPLIED TO THE CREATION OF WEEKLY CLASS TIMETABLE SCHEDULE}

César Daltoé Berci, Nilmaer Souza da Silva, Rafael Bratifich, Renato Carlos Camacho Neves .

Universidade do Oeste Paulista - UNOESTE.

E-mail: rafaelbrattifich@gmail.com

RESUMO - A determinação de uma agenda semanal de aulas é um problema computacionalmente complexo, cujo custo computacional pode aumentar exponencialmente em relação ao número de variáveis envolvidas na solução. Existem no mercado diversos software que constroem essa agenda com base em regras determinísticas. Alternativamente, pretende-se construir essa solução utilizando Algoritmos Genéticos, fazendo uso de sua capacidade exploratória em espaços multidimensionais.

Palavras-chave: Algoritmos Genéticos; Mutação, Agenda.

ABSTRACT - Determining a weekly class schedule is a computationally complex problem whose computational cost can increase exponentially in relation to the number of variables involved in the solution. There are several software on the market that build this timetable based on deterministic rules. Alternatively, we intend to build this solution using Genetic Algorithms, making use of its exploratory capacity in multidimensional spaces.

Keywords: Genetic Algorithm; Mutation; Timetable. 


\section{INTRODUÇÃO}

Os algoritmos genéticos representam uma relevante ferramenta computacional de busca e otimização, com capacidade exploratória relativamente superior em espaços multidimensionais (BERCl, 2008), principalmente quando o objetivo é a busca por pontos de otimalidade global.

Essa característica, associada à sua concepção baseada em processos naturais, que possibilita uma vasta gama de aplicações com diferentes objetivos, torna os algoritmos genéticos uma potencial ferramenta para solucionar o problema proposto, uma vez que, a geração de uma agenda semanal de horários depende de muitas variáveis, com forte interação entre elas.

O principal desafio para formulação proposta é criar uma codificação viável e uma função de avaliação (função fitness) para que o algoritmo genético possa evoluir uma solução satisfatória. Essa etapa se baseia na experiência e observação, não havendo regra pré-definida para construção de um sistema de codificação. Nessa etapa, cria-se um a estrutura representada por um cromossomo, que pode conter valores binários ou reais, no qual cada gene de sua estrutura representa um possível conjunto de informações quer irá otimizar a solução do problema.

Após codificado o problema, pode-se então criar uma população inicial aleatória, que por óbvio, pode conter ou não uma solução viável para o problema ao qual se propõe a resolver. Essa população é então submetida ao processo evolutivo, regida pelo algoritmo genético, visando criar indivíduos que melhor se adequem ao meio virtual proposto, ou, em termos do problema, soluções melhores para o problema de agendamento semanal, principalmente aquelas que evitam conflitos de horário e respeitam restrições prévias.

A seleção e classificação dos individuo - resposta ao problema - no algoritmo genético dá-se através da função de avalição (função fitness) que verifica a resposta proporcionada por cada indivíduo através do seu conjunto de informações (genes) e as classifica apresentando os indivíduos mais aptos da população, ou seja, as melhores soluções para o problema proposto.

\section{METODOLOGIA}

Segundo Timilsina et al. (2015) e Sigl et al. (2003) uma primeira aproximação para a modelação do problema de organização de horários é a adaptação do processo de otimização ao de um problema de corte 3D.

Nessa aproximação as classes devem ser colocadas na estrutura de horários 3D, permitindo uma redução das variáveis binárias presentes e eliminando dimensões excedentes do problema que podem ser consideradas como restrições e, assim, serem empregadas como uma função de avaliação (função fitness) para o problema avaliado. A representação da aproximação ao problema de corte 3D é apresentada na Figura 1.

Figura 1. Modelagem do problema para uma aproximação de corte 3D

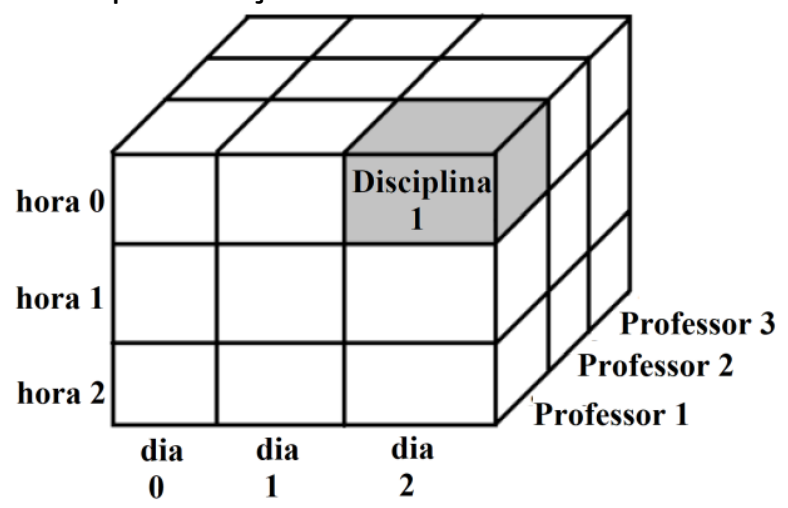

Fonte: (TIMILSINA et al. , 2015).

Nesse processo os conjuntos de informações (genes) dos indivíduos otimizam a organização de horários no cubo e ao final do algoritmo genético é possível encontrar uma solução otimizada para a agenda e sem conflitos de horários entre disciplinas e professores.

\subsection{ALGORITMO GENÉTICO}

O algoritmo genético propõe um modelo heurístico computacional baseado na teoria de evolução das espécies de Charles Darwin e conceitos de genética para a 
otimização de problemas complexos (LINDEN, 2006).

Nesse algoritmo os indivíduos são representados por cromossomo (codificação) compostos por genes que representam as características de solução para o problema avaliado. Um exemplo de um cromossomo binário e real são representados na Figura 2.

Figura 2. Representação do individuo através do cromossomo que carrega as informações para a solução do problema

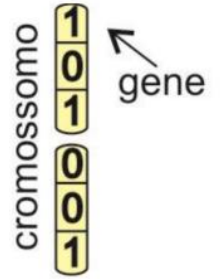

indivíduo

(binário)

Fonte: (BRATIFICH, 2018).

Inicialmente, a população (conjunto de cromossomos) é gerada aleatoriamente e representa um possível conjunto solução para o problema avaliado. Como o algoritmo genético é fundamentado no processo evolutivo, a cada geração a carga genética dos indivíduos é avaliada através da função de avaliação (aptidão) ou função fitness a fim de encontrar os indivíduos mais aptos da população, ou seja, a possível solução que produza a otimização do problema.

Durante as gerações são aplicados operadores genéticos tais como: reprodução e mutação que têm a função de simulam fenômenos vistos na natureza e processo de evolução natural da população, tais como reprodução sexuada e mutação genética (LINDEN, 2006).

0 operador genético de recombinação é semelhante ao crossing-over celular da meiose na meiose no qual os cromossomos se interceptam em algum ponto de sua estrutura e trocam genes aumentando a variabilidade genética dos cromossomos descentes que tornar-se-ão a base da próxima geração. O processo de recombinação e sua comparação como a meiose celular são apresentados na Figura 3.

Figura 3. Representação da recombinação (crossing-over) entre individuo da população.

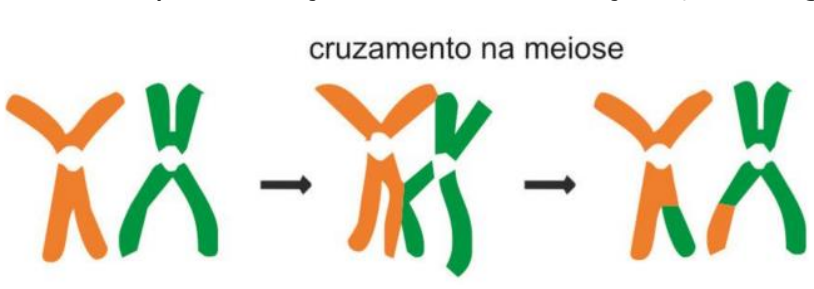

Fonte: (BRATIFICH, 2018).

Os indivíduos da população participantes da recombinação são selecionados através do processo de roleta no qual cada indivíduo é representado na roleta proporcionalmente ao seu índice de aptidão à solução do problema. Dessa forma, os indivíduos mais aptos apresentam maior possibilidade de seleção e transferência de seu material genético para as gerações futuras.

A principal função do crossing over no processo de reprodução é o aumento da variabilidade genética da população.

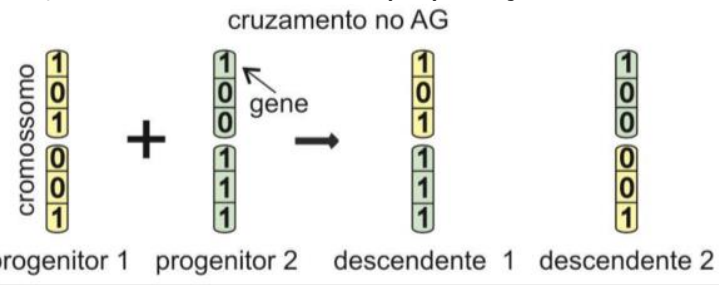

A troca de informações entre indivíduos (cromossomos) com maior aptidão permite ao algoritmo explorar a região próxima da solução ótima local, na qual concentra-se a carga genética da população atual.

Entretanto, nos processos de otimização faz-se necessário encontrar a solução ótima global para o problema - a solução mais próxima da resposta ideal.

Assim, o processo de recombinação ao selecionar os indivíduos mais aptos restringe o espaço de busca na vizinhança da 
solução ótima local encontrada. Dessa forma, é necessário que ocorra uma perturbação no conjunto de solução a fim de explorar novos espaços de busca para aproximar-se da solução ótima global do problema.

Para tal efeito emprega-se o uso de outro operador genético a mutação. 0 operador genético de mutação modifica aleatoriamente o conteúdo de um gene em alguma posição no cromossomo de um indivíduo da população.

A inserção da perturbação (gene mutante) promove o surgimento do indivíduo mutante que possivelmente habilita o algoritmo genético a explorar novos espaços de busca para a solução do problema e assim encontrar novos ótimos locais. Contudo o processo de mutação, assim como no processo evolutivo natural, deve-se restringir a um número extremamente pequeno de indivíduos em cada geração da população a fim de evitar uma busca dispersa no espaço de busca.
No processo de mutação, os indivíduos e os genes são selecionados aleatoriamente para a aplicação do operador.

Ao fim do processo de aplicação dos operadores os descentes resultantes do processo compõem a nossa geração que será selecionada - um novo conjunto de soluções melhor adaptadas as características do problema. No final de $\mathrm{N}$ gerações o algoritmo apresentará o melhor indivíduo que se aproxima da solução ótima global do problema proposto.

A aplicação do algoritmo é resumida através da estrutura apresentada na Figura 4.

Figura 4. Estrutura do algoritmo genético.

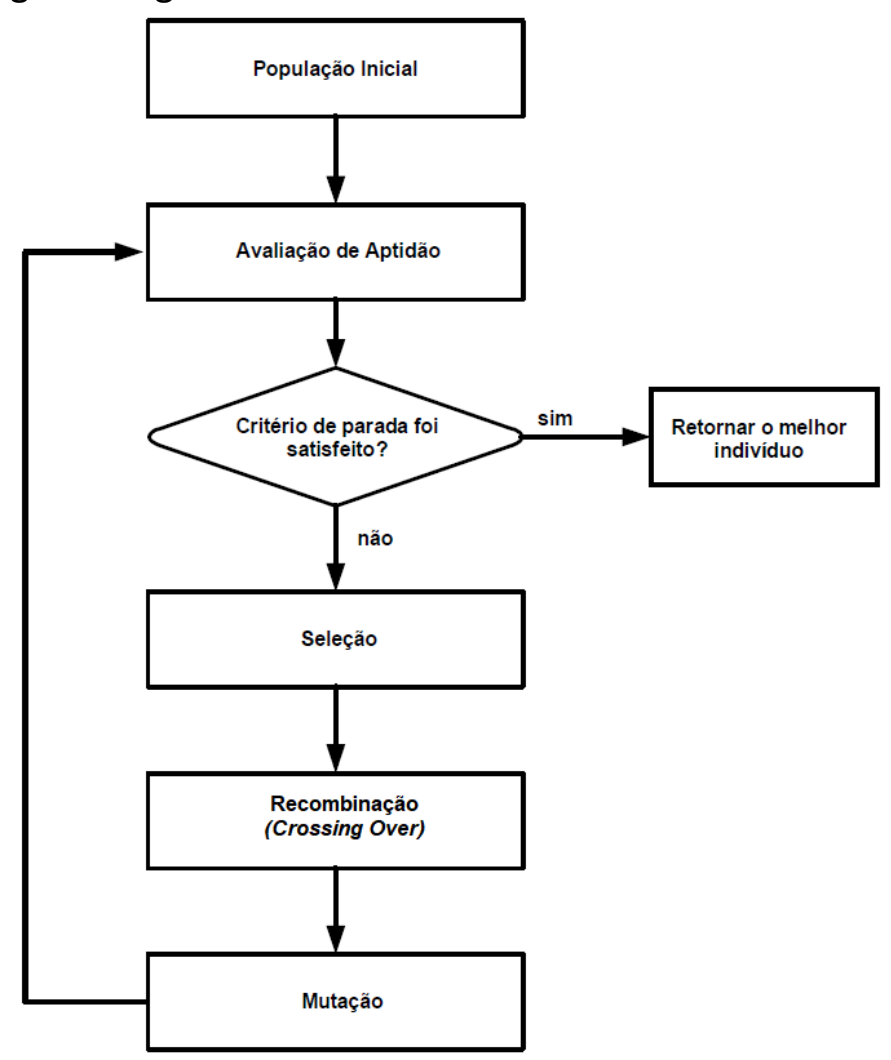

Fonte: Os autores. 


\subsection{CODIFICAÇÃO}

O processo de codificação consiste na definição de um conjunto de informações, com 0 intuito de representar, o mais fielmente possível, o problema de evolução natural proposto por Darwin (DARWIN, 1859).

Dessa forma, tem-se em virtude o objetivo, uma codificação. Assim sendo, diversos autores propõem codificações diferentes, em virtude da aplicação que fazem do algoritmo (GAREY, 1990; GOLDBERG, 1989; HOLLAND, 1975).

Não há, porém, na literatura, registros de uma codificação que se aplique ao problema aqui proposto, portanto, faz-se necessário criar uma.

Considerando então, as variáveis do problema:

1. Classes

2. Disciplinas

3. Professores

4. Horários

5. Restrições

Em linhas gerais, pretende-se alocar as disciplinas de uma classe no horário sendo que para cada uma delas há um professor que, tem suas próprias restrições e não pode, por óbvio estar em das classes simultaneamente no mesmo horário.

Propõe-se então:

I. Formatar os horários das disciplinas em um vetor onde o índice representa o horário semanal;

II. Cada item do vetor representa uma disciplina de uma classe;

III. Cada posição do vetor representará, portanto, um cromossomo;

IV. Os genes serão representados por valores inteiros, sendo um valor para cada disciplina de cada classe a ser alocada no horário.

V. O critério de seleção natural será baseado nos conflitos de horário, ou seja, os indivíduos da população melhor adaptados ao meio serão aqueles que possuírem menor quantidade de conflitos de horário;
VI. Os indivíduos serão selecionados para reprodução com base no método conhecido como roleta (BERCl, 2008).

A codificação proposta assemelha-se, quanto a ótica da forma de representação, a uma codificação binária, logo, pode ser adotados mecanismos de reprodução e mutação tal como nessa forma de codificação (BERCl, 2008).

\subsection{PROCESSO EVOLUTIVO}

O processo evolutivo, responsável pelo desenvolvimento de uma solução para problema, que, dada sua codificação, consistira em uma agenda semanal sem conflitos, é executado da seguinte forma:

1. Cria-se uma população inicial aleatória, onde as disciplinas são alocadas ao acaso no horário;

2. Calcula-se a adaptação dos indivíduos dessa população ao problema proposto;

3. Escolhe-se ao acaso, um número de indivíduos para se reproduzirem, deixando herdeiros de seu material genético para a próxima geração;

4. Escolhe-se ao acaso, um número de indivíduos que irão sofrer mutações;

5. Os pares de reprodução são escolhidos através da roleta; mutação;

6. Aplica-se a reprodução e a

7. Cria-se uma nova geração.

Geração após geração o processo supra descrito é repetido, até que um critério seja atingido.

\subsection{METODOLOGIA DE PESQUISA}

O presente estudo se caracteriza por ser uma pesquisa aplicada. Segundo Vergara (2000), a pesquisa aplicada tem finalidade prática e é originada pela necessidade da resolução de problemas reais, ou seja, concretos. Segundo Danton (2000), este método busca soluções para problemas concretos e que necessitam de solução imediata. Quanto à abordagem, trata-se de 
pesquisa quali-quantitativa, que é amplamente utilizada no campo da Engenharia, uma vez que há necessidade de considerar corretamente os elementos qualitativos da pesquisa de campo realizada. A modalidade de pesquisa quali-quantitativa "interpreta as informações quantitativas por meio de símbolos numéricos e os dados qualitativos mediante a observação, a interação participativa e a interpretação do discurso dos sujeitos (semântica)" (KNECHTEL, 2014, p. 106).

Quanto aos meios, este estudo julgou ser necessária a adoção do método de estudo de caso para favorecer esta investigação. Trata-se, portanto, de uma metodologia indutiva, em que a teoria se comprova a partir de observações empíricas baseadas na interação entre os dados e sua análise. De acordo com Bruyne, Herman e Schoutheete (1977), afirmam que o estudo de caso justifica sua importância por reunir informações numerosas e detalhadas que possibilitem apreender a totalidade de uma situação. A riqueza das informações detalhadas auxilia o pesquisador num maior conhecimento e numa possível resolução de problemas relacionados ao assunto estudado. A fim de coletar informações e avaliar o algoritmo proposto estudou-se sua aplicação na organização do horário semanal de 7 turmas de um curso universitário.

\section{RESULTADOS}

$O$ algoritmo genético descrito foi programado em MATLAB e a título experimental, foi aplicado ao horário semanal de 7 turmas que compartilham entre si um total de 15 professores.

O resultado da aplicação do método proposto pode ser observado no gráfico da Figura 5, que mostra a evolução do erro, aqui representado pela quantidade de conflitos no horário, a cada nova geração.

Outra métrica importante na análise de um algoritmo genético é a preservação da diversidade da população. Para o exemplo proposto, tomou-se como medida desse valor o desvio padrão do valor de adaptação de cada indivíduo da população que é apresentada na Figura 6.

Figura 5. Evolução do erro durante as gerações na aplicação do algoritmo genético

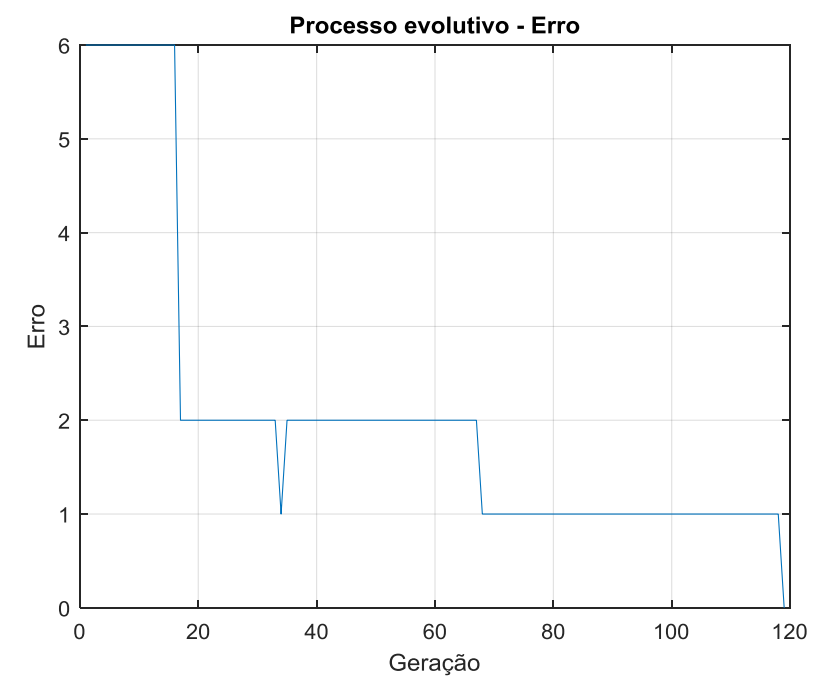

Fonte: Os autores. 
Figura 6. Diversidade ao longo das gerações

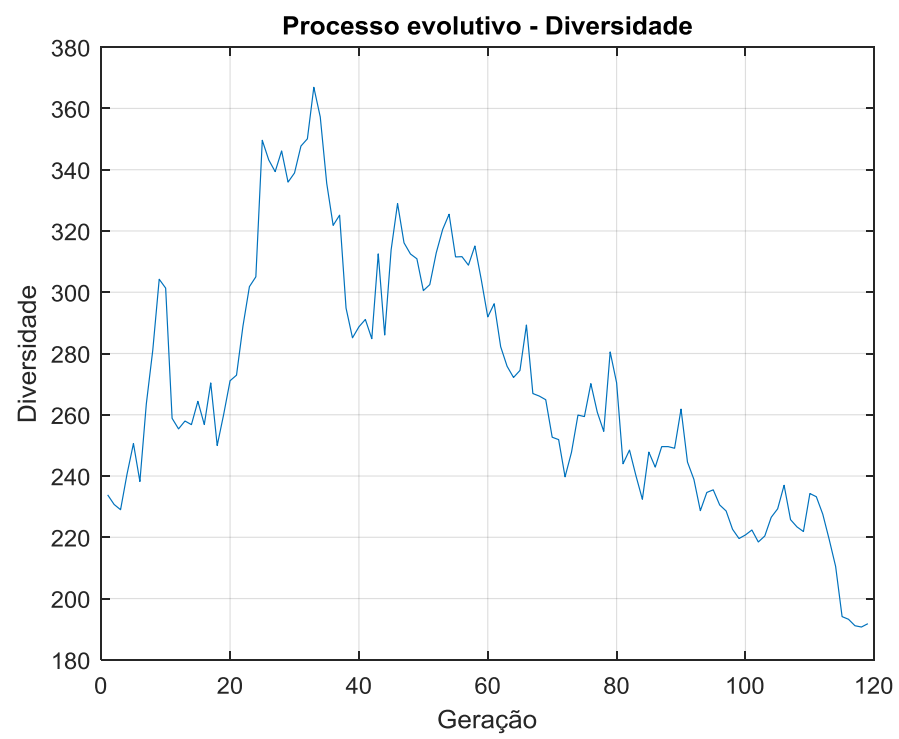

Fonte: Os autores.

\section{DISCUSSÃO}

A partir dos dados da Figura 5 nota-se claramente que a população evoluiu ao longa das gerações, sendo que, na 119a geração, surgiu um indivíduo que representa uma opção de horário semanal onde não há nenhum conflito de horários.

Esse indivíduo presente na 119a geração representa a solução ótima global para o problema. Entretanto, verifica-se que o algoritmo genético apresenta três regiões de ótimos locais exploradas durante a busca.

E a mudança de uma vizinhança de busca para a outra, possivelmente, deve-se ao processo de mutação. Verifica-se na Figura 5 que próximo a 37ạ geração 0 número de conflitos é unitário, porém, devido ao processo de recombinação e a manutenção da carga genética presente nas gerações anteriores o individuo mutante é suprimido e a carga genética na qual há dois conflitos de horário é mantida até próxima da 63a geração.

A partir da 60a geração as caracterizas dos indivíduos mutantes sobressaem-se sobre a carga genética dominante originando uma nova população com apenas um conflito.

A carga genética mantém-se até o aparecimento do indivíduo no qual sua carga genética não apresenta conflito algum de horário presente na 119a geração.

$\mathrm{Na}$ Figura 6 é verificado que a diversidade da população foi satisfatoriamente preservada ao longo das gerações, comprovando a eficácia da codificação proposta.

A diversidade permite ao algoritmo explorar mais eficientemente os espaços de busca evitando a concentração em vizinhanças da solução ótima local.

Entretanto, a diversidade não implica na modificação da carga genética dominante devido ao processo aleatório de seleção de indivíduos pelo método da roleta que favorece os indivíduos mais aptos encontrados naquela população e a porcentagem de indivíduos mutantes ser mínima.

Verifica-se que próximo a 37a geração na qual há o aparecimento repentino da solução com um conflito de horário há um máximo de diversidade na população e após esse máximo há uma redução culminando no aparecimento da solução do problema, ou seja, há uma discreta evidência de convergência genética do algoritmo em direção ao melhor conjunto de solução.

A convergência genética representa a característica do algoritmo em reproduzir os efeitos de seleção natural nos indivíduos ao 
longo das gerações - selecionando os indivíduos mais aptos ao meio durante a gerações. Evidencia-se, também, que a manutenção da relação entre indivíduo e meio promove a alta especificidade da carga genética do indivíduo em direção a solução ótima global do problema. Dessa forma, se o processo de mutação promover indivíduos mais aptos ao meio, a carga genética tende ao longo das gerações deslocar-se para próxima das características do indivíduo mutante.

\section{CONCLUSÕES}

o algoritmo genético proposto para criação de agendas de horário semanal de aulas implementado em MATLAB foi avaliado empiricamente através do horário semanal de 7 turmas que compartilham entre si um total de 15 professores.

A aplicação do algoritmo no horário semanal das 7 turmas mostrou-se satisfatória para a solução do problema de criação de agenda semanal de aulas.

Os operadores genéticos de recombinação e mutação e o processo de seleção contribuíram para a convergência genética da população encontrando a melhor solução para o problema proposto.

Apesar da convergência genética ao longo das gerações verificou-se uma diversidade na carga genética dos indivíduos permitindo explorar um espaço de busca amplo para aproximar-se da solução ótima global. Todas essas características habilitam o algoritmo proposto para realizar o processo de otimização da criação da agenda com eficiência apesar da complexidade numérica do problema.

O processo evolutivo regido pelo algoritmo genético é capaz de evoluir uma solução adequada, gerando um horário semanal livre de conflitos, o que por outros meios pode se tornar uma tarefa árdua e tediosa.

\section{REFERÊNCIAS}

$\mathrm{BERCl}, \mathrm{C}$. D. Observadores Inteligentes de Estado: Propostas. 2008. Dissertação
(Mestrado em Engenharia Elétrica) Universidade Estadual de Campinas, Campinas, 2008.

BRATIFICH, R. Projeto de ilhamento controlado em redes de energia elétrica. 2018. Trabalho de conclusão (Bacharelado em Engenharia Elétrica) - Universidade Tecnológica Federal do Paraná, Cornélio Procópio, 2018.

BRUYNE, P.; HERMAN, J.; SCHOUTHEETE, M. Dinâmica da pesquisa em ciências sociais: os pólos da prática metodológica. Rio de Janeiro: F. Alves, 1977. 251 p.

DANTON, G. Metodologia científica. Pará de Minas: M\&M, 2000.

DARWIN, C. On the origin of species by means of natural selection, or the preservation. London: John Murray, 1859. https://doi.org/10.5962/bhl.title.68064

GAREY, M. A. Computers and intractability: a guide to the theory of NP-Completeness. New York, USA: W. H. Freeman \& Co. New York, 1990.

GIL, A. C. Como elaborar projetos e pesquisa. 3. ed. São Paulo: Atlas, 1995.

GIL, A. C. Como elaborar projetos de pesquisa. 4. ed. São Paulo: Atlas, 2008.

GOLDBERG, D. Genetic algorithms in search, optimization \& machine learning. Reading, MA: AddisonWesley, 1989.

HOLLAND, J. Adaptation in natural and artificial systems. Michigan: University of Michigan Press, 1975.

LINDEN, R. Algoritmos genéticos: Uma importante ferramenta da Inteligência Computacional. Rio de Janeiro: Brasport, 2006. 
SIGL, B.; GOLUB, M.; MORNAR, V. Solving timetable scheduling problem by using genetic algorithms. In: IEEE INTERNATIONAL. CONFERENCE. ON INFORMATION TECHNOLOGY INTERFACES, 25 2003. Proceedings [....] Croatia, Cavtat/Dubrovnik, 2003, p. 519-524.

TIMILSINA, S.; NEGI, R.; KHURANA, Y.; SETH, J. Genetically Evolved Solution to Timetable Scheduling Problem. International Journal of Computer Applications, v. 114 , n. 18, p. $12-$ 17, 2015. https://doi.org/10.5120/20077$\underline{2100}$

VERgARA, S. C. Projetos e relatórios de pesquisa em administração. 3. ed. São Paulo: Atlas, 2000.

KNECHTEL, M. R. Metodologia da pesquisa em educação: uma abordagem teóricoprática dialogada. Curitiba: Intersaberes, 2014. 